\title{
Analyzing the Correlation between Gender Traits and the Perception of Effective Leadership
}

\author{
Phillip Neely $\mathrm{Jr}^{1}$, Ray Muhammad ${ }^{2}$ \\ ${ }^{1}$ Associate Professor of Criminal Justice, Saint Leo University, USA \\ ${ }^{2}$ Adjunct Professor of Business, Saint Leo University, USA \\ Correspondence: Phillip Neely Jr, Associate Professor of Criminal Justice, Saint Leo University, USA
}

Received: May11, 2015 Accepted: July 23, 2015 Online Published: July 28, 2015

doi:10.11114/bms.v1i2.981 URL: http://dx.doi.org/10.11114/bms.v1i2.981

Program Track: Operations Management

\begin{abstract}
As the percentage of women managers has risen in the workforce, so have questions of whether women could effectively manage corporations. This curiosity has yielded studies designed to analyze the correlation between gender and management. Additionally, the research has led to contrary views from one research project to another. In their article, Leadership, Education and Gender Roles: Think manager, Think '?'., Coder and Spiller (2013) reviewed three varying trains of thought from the 1970s through the 1990s to examine how various shortcomings in methodology might impact comprehension and remediation of gender issues and management. The article reviews research that appears to substantiate that when people think manager, they think male. This is followed by data, which suggests that when people think research, we think female and finally research endorsing the train of thought that when people think manager, there is no gender specific thought. Two Indexes developed in the 1970s greatly impacted gender and its correlation to management traits. These were the Schein Descriptive Index (SDI) and the BEM Sex Role Index (BSRI). According Coder and Spiller (20113) results of the Schein Descriptive Index, a test developed by Virginia Schein, indicated the characteristics of women managers more closely resembled males than females.
\end{abstract}

Keywords: leadership traits, correlation, variable, gender and statistical analysis

\section{Introduction}

According to Coder and Spiller (2013), because the research group successfully established personality characteristics for feminine and masculine scales $(\mathrm{p}<.05)$, researchers considered this list valid and used the scale for research. This list of masculine and feminine characteristics was provided to participants who were asked to associate the characteristics with successful management traits. The results were tabulated to measure how likely a masculine characteristic was attributed to "good" leadership as compared to a feminine characteristic. The results indicated masculine characteristics where more likely associated to good leadership traits.

Although these studies provided insight into gender traits and leadership, they were filled with shortcomings. As Coder and Spiller observe, the SDI relied upon studies from the 1950s and 60s for key components of their research. The participants of the study varied from ages five to adult. Additionally, the response of the participants certainly reflected their thinking about women at a time when it would be almost unheard of for a woman to manage a corporation due to blatant sexism. Additionally, Coder and Spiller (2013) report concerns among researchers that the leadership view expressed in the SDI reflects a different dynamic that no longer encompasses today's managerial roles. Therefore, the content validity must be called into question based on the definition provided by Frankfort-Nachmias \& Nachmias (2009) which states the content validity is the degree to which indicators adequately represent the qualities measured.

Although the BSRI received much more research and analysis, several weaknesses were apparent in the study. First, the purpose of the research design as well as clear definitions of femininity and masculinity is vague according to Coder and Spiller (2013). Additionally, the external validity of the BSRI is weak because the survey participants are students. Therefore, the research design lacks heterogeneity which Frankfort-Nachmias \& Nachmias (2009) specify are critical for increased external validity.

As the accepted roles of women and men have evolved over the past half century, many of the assumptions underlying 
the selected items as well as participant responses are no longer valid. As a result, the traits identified by the researchers at the time of inception would not adequately define masculine and feminine roles today. This would certainly affect results where the test to be performed today, because participants would likely not perceive the listed traits in the way intended by the originator.

\section{Literature Review}

Convinced that organizations had no idea how to take advantage of a growing number of women in the workforce, Helgesen (1995) set out to enlighten the world of the capabilities of women. She decided to observe and journal four female executives so we could contrast how they effectively managed employees. As Coder and Spiller (2013) observe, she deduced that women tend to make a web with each thread being a relationship where leadership is the center. This, in contrast to the stereotypical management structure described as hierarchical, where rank is always assigned greater importance.

Key components of this "feminine" oriented leadership were good listening skills, open communication and cooperate team members. The belief is this would lead to increased intangible benefits such as happiness and a strong sense of self-worth and contribution among employees. The end result being longer tenured, more committed employees dedicated to a company cause rather than solely focused on personal gain. This "new" brand of leadership was thought to impact the corporations' bottom lines in a positive way.

The second article identified by Coder and Spiller (2013) is a meta-analysis design to simply test whether there is any difference between women and men leaders in organizations. At the time of the study, researchers Eagly and Johnson were focused was on the more democratic style of leadership common among women as opposed to the more authoritarian style stereotypically utilized by males. Over two decades, Eagly continued her work in this field of study and Coder and Spiller (2013) report she determined in a 2003 article that the "natural transformational leadership traits" exuded by women were advantageous to stereotypical male leadership practices in today's business modus operandi.

Response to these findings was overwhelming with proponents suggesting this was the time for women to shape managerial approaches. Coder and Spiller (2103) reference a study by Sharp which concludes female managers perform favorably when compared to male counterparts in every management criteria measured in the study. Others wrote these findings would mean the demise of the stereotypical male managerial model. They opined this was a part of a gradual process away from male dominated leadership to a point where the "man's man" did not fit in today's society. Although each study provided great enlightenment into the strength of female leadership and established the need for this managerial approach, the studies contained several weaknesses.

Helgesen's 1995 diary study was useful in pointing out several ingenious practices implemented by female corporate leaders. However, she observed only four managers which is a very small group upon which to base studies that are meant to represent an entire gender. A factor that may diminish credibility is the presence of the observer, which is known by the participant. Comfort level undoubtedly would change over time but it is unlikely the manager would perform in the presence of the observer in the exact manner she would alone. While the test group appears credible, the small number of participants makes the transferability of this qualitative study very unreliable. Additionally, because she did not afford the same level of research to male managers to compare the exact difference between the groups being compared or determine whether male managerial dynamics has evolved to implement similar practices to the female group.

The study used respondents from several types of organizations which increased external validity. However, one group of questionnaire respondents consists of undergraduate students enrolled at Purdue University. Each of the students received partial credit for their participation. The fact these are students makes for a weaker external validity because the students don't reflect general society or even the majority of the United States workforce. Additionally, the fact the students are receiving partial credit could jeopardize the integrity of their answers. We can't be sure but some respondents may enroll solely to curry favor with the professor, which would affect internal validity. Finally the findings were challenged for weak internal validity by researchers such as Robert Vecchio. At issue was the accuracy of conclusions based on data including some, which is self-reported.

The third line of research analyzed by Coder and Spiller (2013) demonstrates there is no significant difference between males and females. They reference Shimanoff and Johnson's 1991 article supporting the belief that males and females adapt and perform key component of organizational leadership with equal skill. Robinson and Lipman-Blumen support this position advancing the position that neither male nor female can claim a position that inherently is a property of gender that makes them more suited for management than the opposite sex according to Coder and Spiller (2013).

Kim and Shim (2003) also provide insight into leadership roles as the correlate to gender. In order to understand gender differences as related to organizational leadership, they studied job function as well as personal values and other 
variables. Tests were administered to a population of retail managers with two research objectives in mind: (1) to determine whether gender differences exist in leadership styles among retail managers and executives, (2) to determine how gender, combined with variables such as education, experience and personal values affects leadership style. For historical context for research performed using Quinn's theory of Leadership Functions, Kim and Shim (2003) reference researchers performing several different studies which show corroborative findings that female and male leaders are perceived to be equally effective leaders by co-workers on varying levels.

In this study, Kim and Shim (2003) hypothesize (hypothesis 1) that males and females will emphasize different leadership roles. They further hypothesize that in cases where leadership roles differ based on gender, the groups will also differ in reference to (hypothesis 2a) certain personal values (hypothesis 2b) job characteristics and (hypothesis 2c) other personal variables (Kim and Shim, 2003).

\section{Methodology}

A random sampling was drawn from 1400 managers obtained from a mailing brokerage firm. The sampling was made to be representative of the store population in each state with various management levels represented based on the number of headquarters in each area. The respondents $(\mathrm{n}=205)$ varied in age with $63 \%$ of respondents being male and $88 \%$ percent of respondents being white. The average experience level of the respondents was 18 years with a salary range that varied widely.

Each respondent answered a questionnaire by performing a self-assessment. Respondents read a list of statements describing management functions and assigned a value of 1 to 7 for how often they engaged in each management function. Additionally, the following four value categories were listed a priori: social, growth, achievement, security. The subject was asked to list how important each factor was in their life as a guiding principle.

The results of the multivariate analysis of the correlation between gender and leadership style divulged that female and male managers differed in the perceived leadership roles. Therefore, according to Kim and Shim (2003), hypothesis 1 was accepted. Interestingly, no gender differences were found in five of the eight leadership categories. The F-score indicated the category labeled mentor had the largest disparity between male and female groups.

Kim and Shim (2003) admit a weakness of the study is it is limited to the retail field. The authors suggest expanding the research to other business sectors. Additionally, the sample was effectively drawn from a single mailing brokerage firm. Perhaps the sample should be drawn from a number of sources because most retail corporations do not use the same firm. Lastly, the experience level of those surveyed is 18 years. This is probably a lot longer than average. It also could mean those being sampled have refined their managerial craft to the level they have moved to "center" procedurally over their tenure.

Another perspective on the correlation of gender and leadership is provided in the work entitled, Is Transformational Leadership Always Perceived as Effective? Male Subordinates' Devaluation of Female Transformational Leaders, by Ayman, Korabik, and Morris (2009). This research examines the correlation between a leaders self-report of transformational leadership compared to ratings male and female subordinates. Ayman, Korabik \& Morris (2009) found that male subordinates differ in their opinion of female leaders significantly than female subordinates. On the other hand, the study showed male and female subordinates share a similar opinion of the effectiveness of male leaders. This study offers a unique perspective in that the researcher considers gender as a moderator of the relationship exploring three possible transformational effects: 1) is there an effect based on the gender of the leader; 2) is there an effect based on the gender of the subordinate; 3 ) is there an effect based on the composition of the leader-subordinate dyad? This third element is the crux of the research study.

The authors of the study (2009) hypothesize the relationship between transformational leadership behavior and leadership will be influenced by gender in the leader-subordinate dyad. More specifically, Ayman et. al (2009) believes subordinates will not correlate the transformational leadership of male leaders and their perception of effective job performance. They suppose that the transformational leadership ability of female leaders will affect the subordinates' impression of their job performance. Specifically, the belief is that male subordinates will correlate the two with a more negative impression and rating than female subordinates.

The research method includes 293 questionnaires sent to managers in three Canadian industrial organizations as well as vice-principals of Canadian primary and secondary schools. Researchers received 155 responses consisting of 77 males and 78 females. According to Ayman et. al (2009), questionnaires were sent to an even number of men and women, then matched for position and level. An additional 291 questionnaires were returned by teachers and industrial organization subordinates.

\section{Finding \& Recommendations}

The findings of the research with a p level of .09 were as follows according to Ayman et. al.(2009): for male leaders, 
transformational leadership was not significantly related to performance ratings from male or female subordinates. However, for female leaders, transformational leadership had a significant negative relationship to performance rating when the subordinate was a male. The relationship was positive but not to the critical level necessary to achieve significance.

One weakness of the study is it relied upon self-reporting by all participants. The researcher cannot be sure the respondent actually provided the date his/herself or relied on an assistant to provide the answers. Additionally, the answers are skewed by the perception and mood of the respondent at the time of completion which could vary from one day to the next.

Himanshu Rai (2009) researched what level of positive effect an organizational leader's gender has on subordinates' through ingratiation. He hypothesized that subordinate ingratiation and subordinate gender will interact such that Leader Member Exchange Quality (LMX) will have a stronger positive influence on female subordinates than male subordinates. According to Rai (2009), this research is grounded in Sparrowe and Liden's social exchange theory which suggests that in relationships, people seek to maximize benefits and minimize costs. Likewise, an interpersonal relationship develops between supervisor and subordinate which offers something of value to both parties. The more the benefits outweigh the costs of the relationship, the more positive the perception and commitment to the relationship. The more effective the manager at techniques that influence the employee, the more successful the manager and the tool focused on in this study is ingratiation. The researcher defines ingratiation as including the following behaviors designed to proactively influence a person: agreeing with opinions, offering praise for achievement (present and past), emphasizing unique qualifications, being sensitive to inconveniences caused by requests, sympathizing with the mood of the person. (Rai, 2009)

The sampling for the study consists of executives of varying levels and departments within a large organization in Eastern India. Additionally, 164 subordinates responded to the questionnaire presented by Rai (2009). The scientist also reported tenure of 4.36 years on average for the respondents. One questionnaire examined the subordinates' perception of ingratiation while a scale measured the leader member exchange quality perception of the subordinate. The Pearson Correlation conducted by Rai (2009) indicated a high correlation between ingratiation and LMX quality. Results supported the alternative hypothesis that ingratiation has a stronger impact on LMX quality for female subordinates than their male counterparts.

A weakness of the study which is acknowledged by Rai (2009) is the research is conducted on executive employees and may not apply to lower level management positions. Additionally, because the study relies on self-reported data, the findings are subject to the perception of each individual. Lastly and perhaps the largest threat to validity is the cultural bias in India which does not view women in leadership positions as favorably as men. This perception undoubtedly affects all men as well as women and their stereotypical sex roles.

Another source of reference for the proposed research is contributed by Stoker, Van der Velde and Lammers (2011) in the research article entitled, Factors Relating to Managerial Stereotypes: The Role of Gender of the Employee and the Manager and Management Gender Ratio. The analysis is called for because of the increasing numbers of female managers. Because traditional studies have shown the common gender stereotype that male managers are typically better than females, the scientists sought to examine this phenomena based on managerial ratio. Specifically, the purpose of the project is to explore whether the gender of the manager, the gender of the employee and the gender ratio of managers in an organization has an influence on managerial stereotyping by employees.

Over 3,000 participants responded via electronic questionnaire. The first test (a mixed design ANOVA) performed by Stoker et. al. (2011) determined that while male employees find feminine characteristics significantly less attractive than females, the two groups do not differ significantly in their perception of masculine characteristics. The next test, examined the employee response based on manager gender. Results showed that those with a male manager found feminine characteristics less attractive while those with female managers did not differ significantly in their view of masculine traits when compared with employees with a male manager. Finally, a test for correlation between the number of female managers present and employee preference for feminine characteristics revealed that there was a positive correlation between the two variables. The overall conclusion reported by Stoker et. al. (2011) was: female employees, staff members with female managers and those in companies with a greater percentage of female managers have a more androgynous stereotype of a "good" leader.

Stoker et. al (2011) points out limitations to the study such as the participant pool being restricted to a homogenous group of highly educated employees. It appears likely these respondents occupy white collar positions and the results cannot be generalized to blue collar workers. Additionally, the option to enter "no preference" as a response to gender preference in a manager may lead to responses that are not factual unless those who select that response are exactly equal in their desire for a manager of either gender; this is highly unlikely. Finally, the suggestion that increasing the 
number of female managers in an organization is the way to increase androgynous stereotypical behavior, while possibly true, is impractical and may lead to reverse discrimination.

Many successful business men agree the most important asset of a company is its employees. Successful companies create an environment which makes the workplace attractive to potential employees and beneficial to long term staff. Therefore, corporations are constantly searching for better understanding of the factors that have a positive influence employee performance. Increased productivity among employees can be the difference between the success and failure of a corporation at worse, and often can mean annual gains or losses of millions of dollars.

To this end, human resource departments were created to regularly perform various analytics to assess employee moods, thoughts and opinions. In the past, analytics focused primarily those factors that affect employee well-being primarily to reduce liability for labor law infractions such as racial discrimination, sexual harassment and age bias. While this methodology has been effective at protecting companies from litigation, it has not necessarily maximized the greater corporate potential which is the hired workforce.

Ben Franklin said "an ounce of prevention is worth a pound of cure." In other words, it is better to be pre-active than reactive. Whether it is personal or corporate health, the principle applies and social scientists as well as board members are now considering proactive methods to understand what makes a healthy work environment and a healthy employee. Today, companies seek more feedback from employees than ever before. Human Resource have inquiries may be formal or informal, verbal or written and many times are anonymous. They include tools such as interviews, questionnaires, surveys, workshops, and observation all designed to enlighten corporate executives to what stimuli the employee best responds. Although it may not be thought of as such, corporations are employing informal social science research designs to explore various phenomena which effect the work environment. And much of the research seems to support the belief that effective leadership is perhaps the single most critical element of a successful business practice today.

Company leaders set the tone and expectation level for employees and help to foster an atmosphere in which the employee is motivated and empowered. They serve as guide and advocate for those under their authority. But what do employees feel makes an effective leader? Which leadership characteristics are most important to those being governed? With more women occupying managerial positions than ever before, what correlation if any, exists between gender trait and the perception of effective leadership? How do we make the general workplace impression of a "good" organizational leader non gender based?

As Muhammad (2014b) writes in a prerequisite assignment: to better analyze these questions, I have selected a quantitative, quasi-experimental research design. Our research will test Quinn's social exchange theory in correlation with a similar design to the test design advanced by Schein which lists sex role stereotypes. The research should provide enlightenment into whether there is significant correlation between male and female subordinates and their perception of what is "good" leadership. Once a pre-test is administered, a class will be administered to the experimental group followed by a post-test to see if there is a significant correlation between education and a more androgynous perception of successful leadership qualities.

The method will include a questionnaire administered to participants who receive a questionnaire which contains masculine and feminine attributes. They will identify how well the characteristics identified reflect a "good" leadership by answering on a five point scale ranging from "very characteristic", "somewhat characteristic", "neutral", "somewhat uncharacteristic" and "very uncharacteristic". In order to avoid researcher bias, feminine and masculine traits will be those defined by the Planned Parenthood website.

The chosen research project will consider what effect the specified training program will have on participants in an experimental group compared to the control group. In order to determine the estimated sample size needed to make a reliable inference, $\mathrm{M}$ effect sizes from two studies were used. The data and results are as follows:

I. Alpha value is the standard 05 .

II. Power $=.80$

III. Estimate Effect Size $=34$

The effect size is determined based on $\mathrm{M}$ effect sizes of 0.32 and 0.67 from two similar studies. The average of the two estimates is: 49.5 , rounded to .50 for the chart. Because there are research results available from two related samples, the first chart entitled "t test for One-Sample or Two Related Samples" is referenced. The Cohen=s d used is found by reading down the left column to value $=.80$, then across to value $=.50$ as instructed by Burkholder (n.d.). The result is Estimated Effect Size $=34$.

Based on this information, the research will test 34 participants in each group (control and experimental). The first chart 
is most appropriate because we are examining a single effect (the training) on one group against a control. We are not comparing two independent factors and are not making a correlation between several behaviors in the study. The total of 34 participants in each group is also not cost or time prohibitive while allowing the researcher to perform an effective research study. We are also able to draw this number of participants from the field of 100 employees to whom we have access.

The sample will be drawn via convenience sampling. The researcher can access employees from two companies and will be in a position to provide training to the participants, which is critical to the research design. From this population, a simple random sample will be selected. The sampling design is a non-probability sample which according to Frankfort-Nachmias \& Nachmias (2008) means there is no way to assure presence of each unit in the sampling. The research seeks to determine whether workers employees associate masculine leadership qualities with more capable leadership than feminine characteristics. The study will include participants from two companies but these will be professional companies which will not include service industry companies. Additionally, workers of some level of academic achievement and rank will not be included in the study. (Muhammad, 2014b)

The research question to be explored is: $\mathrm{Q}_{1}$-Does education intervention affect employee perception of gender as related to what is considered a "good" leader? This study and research design was chosen because of the time and nature of the studies which provide the framework for the current contribution. The researcher feels the best beginning point is a basic quasi-experimental design which will contain data which can be built upon based on early results.

Null Hypothesis or $\mathrm{H}_{0}$-There will be no significant difference in employee perception of masculine and feminine traits as related to a "good" leader.

Alternate Hypothesis or $\mathrm{H}_{1}$-There will be a significant difference in employee perception of masculine and feminine traits as related to a "good" leader.

The Independent Variable (IV) is a cognitive learning workshop, which will be enacted on the experimental group of participants. The Dependent Variable $\left(\mathrm{O}_{1}\right)$ is the measurement of the pre-test. The second Dependent Variable $(\mathrm{O} 2)$ is the measurement of the post-test. The difference in the control group's pre and post-test scores is the level of change that should be expected without the introduction of the Independent Variable. The difference in the experimental group's pre and post-test scores is the level of change that should be expected as a result of the introduction of the Independent Variable (treatment). The difference between the changes in score of the experimental and control groups is the effect of the treatment

\section{Conclusion}

The internal validity is enhanced because the groups experience the same circumstances in pre-test and the same time span of thirty days for the post-test. The sampling is large enough and the test period is short enough that drop-out rate should be minimal and easy to overcome. Each group will be assessed in the same manner by the researcher, which should also strengthen the internal validity of the research. Lastly, the mood, personal morals, and predisposition of the respondents have not been accounted for in this study. This will negatively affect the internal validity of the study.

The external validity is affected by the sampling size, which is small. The sampling is pulled from the population of three professional corporations, which means the results may not be transferable to blue collar employees. The sampling is limited to lower level employees as opposed to a wide range and level of employees.

A limitation of the study is that the research design is a pre-test/ post-test control group design. A t-test for Independent Samples may better reveal the correlation between variables and a multivariate analysis could provide valuable insight into the relationship of the variables of the study. Additionally if other factors such as personal values are observed among the variables, a more comprehensive understanding of the various factors that influence the pre-disposition of the participant may be attainable. All participants will sign a consent form to be a part of the study. Although there are no serious ethical concerns, full disclosure will be made so that the participants have a full general awareness of the project and are able to make a conscientious decision to move forward.

The study offers a practical contribution because it analyzes education as a tool of making the perception of "good" leadership more androgynous. If a correlation can be shown, the results will allow corporations as well as learning institutions to positively affect the way the general population perceives the capability of male and female managers. This possibility makes the study important for researchers, instructors and students at higher learning institutions, as well as employees and corporate leaders. The affect the study would have on social change is to provide a platform for the feminine as well as masculine characteristics of leadership to be better appreciated by male and female subordinates.

\section{Author Information}

Dr. Phillip Neely is the recipient of the Doctor of Philosophy in Public Policy and Administration from Walden University 
and the Masters of Science in Public Administration from Central Michigan University. He is an Associate Professor at Saint Leo University in Duluth, Georgia. Dr. Neely's expertise comes in the field of criminal justice and public policy.

Ray Muhammad is the recipient of the Masters of Science in Accounting from Walden University and Bachelors in Sociology from Florida State University. He is an Adjunct Professor at Saint Leo University in Duluth, Georgia. Ray Muhammad's expertise comes in the field of accounting and business management.

\section{References}

Ayman, R., Korabik, K., \& Morris, S. (2009). Is Transformational Leadership Always Perceived as Effective? Male Subordinates' Devaluation of Female Transformational Leaders. Journal of Applied Social Psychology, 4, 852. http://dx.doi.org/10.1111/j.1559-1816.2009.00463.x

Coder, L., \& Spiller, M. S. (2013). Leadership education and gender roles: think manager, think '?'. Academy Of Educational Leadership Journal, 2, 21.

Eagly, A. H., \& Johnson, B. T. (1990). Gender and Leadership Style: A meta-analysis. Psychological Bulletin, 108, 233-256. http://dx.doi.org/10.1037/0033-2909.108.2.233

Frankfort-Nachmias, C., \& Nachmias, D. (2008). Research methods in the social sciences (7th ed.). New York: Worth.

Helgesen, S (n.d.) The Female Advantage: Women's Ways of Leadership. $\mathrm{http} / /$ books.google.com/books?hl=en\&lr=\&id=jQbdx7V7sFEC\&oi=fnd\&pg=PR13\&dq=Helgesen+study+THe+fe male+advantage\&ots=cbmes6SMdI\&sig=55_PGXzCGUi5x cpj9mCBCngNiT4\#v=onepage\&q=Helgesen\%20stud $\mathrm{y} \% 20 \mathrm{THe} \% 20 \mathrm{female} \% 20$ advantage $\& \mathrm{f}=$ false

Kim, H., \& Shim, S. (2003). Gender-Based Approach to the Understanding of Leadership Roles Among Retail Managers. Human Resource Development Quarterly, 14(3), 321-342. http://dx.doi.org/10.1002/hrdq.1069

Muhammad, R. (2014a). Quantitative Reasoning. Quantitative Reasoning and Analysis. Walden University

Muhammad, R. (2014b). Quantitative Reasoning. Quantitative Reasoning and Analysis. Walden University

Rai, H. (2009). Gender differences: ingratiation and Leader Member Exchange Quality. Singapore Management Review, 1,63 .

Stoker, J. I., Velde, M., \& Lammers, J. (2012). Factors Relating to Managerial Stereotypes: The Role of Gender of the Employee and the Manager and Management Gender Ratio. Journal Of Business And Psychology, 1, 31. http://dx.doi.org/10.1007/s10869-011-9210-0

\section{$((c))$ EY}

This work is licensed under a Creative Commons Attribution 3.0 License. 